\title{
Teaching the Hate U Give: Using Film to Guide Difficult Conversations about Race that Empower Young People
}

\author{
Nina C. Lasky, Ed.D. \\ Teachers College, Columbia University
}

\begin{abstract}
The purpose of this session is to promote educational equity by using film to explore profound issues around race, justice, equity and empowerment. In the United States, data shows that by 2020 more than $50 \%$ of public-school students will be culturally diverse yet $80-85 \%$ of public-school educators continue to be white women. Teachers are struggling with how they can better serve students who are from different cultures. There are many factors contributing to the disproportionate number of black and brown students in our national academic achievement gap. Systemic racism plagues the foundation of our nation yet we continue to ignore this in our educational system. Through building curricula around film, in this case The Hate U Give, my hope is to give teachers an opportunity to identify values and beliefs that manifest in their classroom and explore strategies for using film to build empathy, empower students and cultivate more equitable outcomes. This curriculum supports students and teachers to gain a deeper understanding of the historical background and racial injustice the film is rooted in. The challenge is to make schools a place where all feel free to take risks and be authentic. Film becomes a safe third space, taking the focus off the teachers or students, facilitating conversations that are constructive and transformative. Learning activities centered around the issues raised in this particular film can provide opportunities to develop empathy, the ability to work both collectively and independently and inspire students use their voice to transform our world.
\end{abstract}

Key words: Curriculum; Disproportionality; film; social-justice; youth 